\title{
Efeitos da Irrigação e Adubação Nitrogenada sobre a Massa de Forragem de Cultivares de Panicum maximum Jacq. ${ }^{1}$
}

\section{Érica Matsumoto de Souza ${ }^{2}$, Olair José Isepon ${ }^{3}$, João Batista Alves ${ }^{3}$, João Francisco P. Bastos ${ }^{4}$, Ronaldo Cintra Lima ${ }^{5}$}

\begin{abstract}
RESUMO - Foi conduzido um experimento no período de 06/09/2000 a 18/09/2001, para se avaliar os efeitos da irrigação e da adubação nitrogenada sobre a massa de forragem de cinco diferentes cultivares de Panicum maximum Jacq. Avaliaram-se cinco cultivares (Guiné, Colonião, Mombaça, Tanzânia e Centauro), três doses de nitrogênio (50, 75 e $100 \mathrm{~kg}$ de N/ha/corte) e a presença e ausência de irrigação, em delineamento de blocos casualizados, em esquema fatorial de 5 x 3 x 2, com quatro repetições. A irrigação promoveu aumentos significativos nas produções de massa de forragem (PMF) para todos os cultivares. Na estação chuvosa (OUT/00 a MAR/ 01 ), as doses de 75 e $100 \mathrm{~kg} / \mathrm{ha}$ de $\mathrm{N}$ por corte proporcionaram maiores PMF que a de $50 \mathrm{~kg} / \mathrm{ha}$ de $\mathrm{N}$ por corte. O cultivar Mombaça apresentou maior PMF, na presença de irrigação, que os demais cultivares, enquanto, na ausência, todos os cultivares apresentaram produções semelhantes. Na estação seca (MAI/01 a AGO/01), a irrigação promoveu aumento significativo na PMF, em relação ao tratamento sem irrigação. À medida que se elevaram as doses de N, aumentou-se a PMF, enquanto, na ausência de irrigação, houve diferença entre as doses de 50 e $100 \mathrm{~kg} /$ ha de N por corte. Observou-se o efeito positivo da irrigação sobre a PMF a partir do final da estação seca, quando as temperaturas começaram a se elevar e o fotoperíodo provavelmente não era mais fator limitante; ou seja, foi possível antecipar a estação de crescimento das forrageiras a partir do mês de agosto, com PMF média de 1 a 2 t/ha, para a dose de $75 \mathrm{~kg} /$ ha de $\mathrm{N}$ por corte e de até $3 \mathrm{t} / \mathrm{ha}$, na dose de $100 \mathrm{~kg} / \mathrm{ha}$ de $\mathrm{N}$ por corte, em relação ao tratamento sem irrigação.
\end{abstract}

Palavras-chave: Centauro, Colonião, Guiné, Mombaça, Tanzânia

\section{Effects of Irrigation and Nitrogen Fertilization on Dry Matter Yield of Panicum maximum Cultivars}

\begin{abstract}
This trial was carried out from September $6^{\text {th }}(2000)$ to September $18^{\text {th }}$ (2001) to evaluate the effects of irrigation and nitrogen fertilization on drymatter yield of five different cultivars of Panicum maximum. Five cultivars (Guiné, Colonião, Mombaça, Tanzânia and Centauro) under three nitrogen rates $(50,75$ and $100 \mathrm{~kg} / \mathrm{ha} /$ cut of $\mathrm{N})$, with and without irrigation were evaluated. The experimental treatments, the combination of a $5 \times 3 \times 2$ factorial, was allocated in a completely randomized design with four replications. Irrigation brought about significant drymatter (DM) yield of all cultivars. In the rainy season (October/00 to March/01), highest DM yield was observed on plot receiving 75 and $100 \mathrm{~kg} / \mathrm{ha} / \mathrm{cut}$ of $\mathrm{N}$. Under irrigation Mombaça cultivar was the most productive cultivar but without irrigation no difference was observed among the cultivars. During the dry season (May/01 to August/01), the drymatter yield of irrigated plots increased significantly as the nitrogen levels increased, whereas without irrigation difference between the rates of $50 \mathrm{and} 100 \mathrm{~kg} / \mathrm{ha} / \mathrm{cut}$ of N was observed. A positive effect of irrigation was obtained from the final of dry season, as the temperature increased and probably the photoperiod was not a limiting factor. Forage management can be anticipated by reducing growth season from August, with DM yield from 1 and $2 \mathrm{t} / \mathrm{ha}$, with $\mathrm{N}$ rate of $75 \mathrm{~kg} / \mathrm{ha} / \mathrm{cut}$, to $3 \mathrm{t} / \mathrm{ha}$, with the highest rate, in relation to the treatment without irrigation.
\end{abstract}

Key Words: Centauro, Colonião, Guiné, Mombaça, Tanzânia

\section{Introdução}

As pastagens são consideradas a forma mais prática e econômica de alimentação dos bovinos e, portanto, desempenham papel fundamental nos sistemas de produção de carne e/ou de leite.
Gramíneas do gênero Panicum se destacam pela sua elevada produção de massa, sendo alvo de várias pesquisas. Segundo Aronovich (1995), estima-se que a espécie já ocupou área superior a seis milhões de hectares no Brasil (em sua grande maioria do capimcolonião). Provavelmente, essa área hoje seja menor,

\footnotetext{
1 Parte da dissertação de mestrado da primeira autora.

2 Aluna de Mestrado em Zootecnia - FE/UNESP - Ilha Solteira - SP - Bolsista da CAPES. E.mail: e.matsumoto@bol.com.br

${ }^{3}$ Prof. Adjunto Dep. de Biologia e Zootecnia - FE/UNESP - Av: Brasil, 56 - CEP: 15385-000 - Ilha Solteira - SP - Caixa Postal: 31.

E.mail: isepon@bio.feis.unesp.br; jbalves@bio.feis.unesp.br

${ }^{4}$ Prof. Dr. Dep. de Biologia e Zootecnia - FE/UNESP - Av: Brasil, 56 - CEP: 15385-000 - Ilha Solteira - SP - Caixa Postal: 31

E.mail: fbastos@bio.feis.unesp.br

${ }^{5}$ Aluno de graduação em Agronomia -FE/UNESP. E.mail: rclima@agr.feis.unesp.br
} 
pois problemas de manejo e fertilidade do solo, assim como o advento das braquiárias caracterizadas por gramíneas menos exigentes em fertilidade do solo, têm prejudicado a utilização dessa espécie.

No território brasileiro, a espécie continuará desempenhando papel importante nas áreas em desmatamento ou que justifiquem o emprego de fertilizantes, em razão de sua elevada produção e qualidade (Aronovich \& Rocha, 1985). Para obtenção de elevada quantidade de forragem, é necessário considerar que as gramíneas são tão ou mais exigentes que as culturas tradicionais. Portanto, para a exploração intensiva das pastagens, a correção e a adubação estão entre os fatores determinantes do nível de produção das pastagens no verão.

Segundo Jank (1995), todos os capins sofrem redução na produção de um ano para outro se não forem repostos os nutrientes retirados do solo, tendo observado, nos cultivares "Tanzânia-1" e "Mombaça", reduções de 48 e $45 \%$, respectivamente, na produção do primeiro para o segundo ano, enquanto, no capimcolonião, houve declínio de $65 \%$.

A adubação apresenta efeito marcante sobre a produção das forrageiras. A maior eficiência no uso do $\mathrm{N}$ e as respostas em termos de produção somente ocorrerão quando os demais nutrientes estiverem em equilíbrio na solução do solo, gerando um ambiente ótimo para os processos de absorção por parte da planta forrageira (Corsi \& Nussio, 1993).

Favoretto et al. (1988) empregaram os níveis de 0, 50 e $100 \mathrm{~kg} /$ ha de $\mathrm{N}$ em capim-colonião, e, avaliando as respostas durante o verão (novembro-março), constataram significativo aumento na produção de MS, em função da elevação dos níveis de N.

Outro importante fator é a estação da seca, em que as gramíneas tropicais apresentam baixa disponibilidade de forragem, obrigando os produtores a suplementarem o rebanho, elevando, assim, o custo de produção. Trabalhos desenvolvidos na região do Brasil Central comprovam que 75 a $85 \%$ da produção de matéria seca total anual ocorrem na época quente e chuvosa (outubro a março) e de 15 a 25\%, na época seca (abril a setembro).

Pedreira (1973), estudando a estacionalidade de produção de quatro capins tropicais ao longo de cinco anos, obteve produções de 700 a $2.200 \mathrm{~kg} / \mathrm{ha}$ de MS ( $13 \%$ do total anual), com capim-colonião, durante o inverno, e de 8.800 a $13.400 \mathrm{~kg} / \mathrm{ha}$, durante o verão ( $87 \%$ do total anual), com taxa de crescimento de $64 \mathrm{~kg} / \mathrm{ha} / \mathrm{dia}$ de MS no verão e somente $2 \mathrm{~kg} / \mathrm{ha} /$ dia de
MS no inverno. Ao avaliar cinco níveis de adubação $(0,100,275,756$ e $2.079 \mathrm{~kg} / \mathrm{ha} /$ ano de N), Pinheiro (2002) observou produções médias de MS do capimtanzânia de 929, 1.162, 1.779, 2.901 e $3.553 \mathrm{~kg} / \mathrm{ha}$, respectivamente, no verão, e de 543, 668, 874, 1.323 e $1.479 \mathrm{~kg} / \mathrm{ha}$ de MS, no inverno. Ao avaliar a produção do capim-tanzânia irrigado, o autor observou aumento na produção de MS com a elevação das doses de $\mathrm{N}$, registrando valores de 6.819, 8.485, $12.397,19.798$ e $23.687 \mathrm{~kg} / \mathrm{ha} /$ ano de MS para as doses de $0,100,275,756$ e $2.079 \mathrm{~kg} / \mathrm{ha} /$ ano de N.

Guelfi Filho (1972), ao avaliar a prática da irrigação em capim-elefante, observou acréscimo de $48 \%$ na produção de MS durante o inverno em relação ao tratamento sem irrigação. Benedetti et al. (2001) observaram, para o capim-tanzânia sob irrigação, cortado a cada 30 dias, produções de 5,7 t/ha de MV, na época chuvosa, e 2,9 t/ha de MV, na época seca.

A baixa produção de massa de forragem durante o inverno, tem sido apontada como um dos fatores que mais contribuem para a baixa produtividade dos rebanhos, sendo responsável pela queda acentuada na produção leiteira, pela perda de peso dos animais de corte e pela grande redução na capacidade de suporte. As baixas temperaturas noturnas (abaixo de $15^{\circ} \mathrm{C}$ ) nas regiões dos trópicos e subtrópicos são apontadas como os principais agentes causadores da estacionalidade de crescimento das plantas forrageiras tropicais (Bryan \& Sharpe, 1965).

$\mathrm{Na}$ tentativa de se elevar a produção de forragem durante a época seca e amenizar os efeitos dos veranicos, a irrigação das pastagens tem sido implantada em inúmeras propriedades no Brasil Central. Entretanto, pouco se conhece sobre a produtividade da planta forrageira, sobretudo no inverno. Deste modo, este trabalho foi realizado para se avaliar o efeito da irrigação e da adubação nitrogenada sobre a produção de forragem de cinco cultivares de Panicum maximum.

\section{Material e Métodos}

O experimento foi conduzido na Fazenda de Ensino e Pesquisa da Faculdade de Engenharia - Campus de Ilha Solteira, no período de 6 de setembro de 2000 a 19 de setembro de 2001. Segundo a classificação de Köppen, a região possui clima do tipo Aw, definido como tropical úmido, caracterizado por estação chuvosa no verão e seca no inverno, com temperatura, precipitação média anual e umidade relativa médias 
anuais de $24,5^{\circ} \mathrm{C}, 1.232 \mathrm{mme} 64,8 \%$, respectivaemente (Hernandez et al., 1995).

Avaliou-se a produção de matéria seca de cinco cultivares de Panicum maximum, três doses de nitrogênio, com e sem irrigação, constituindo um fatorial 5 x 3 x 2, em delineamento de blocos casualizados, com quatro repetições, totalizando 30 tratamentos. Os cultivares estudados foram Guiné, Colonião, Mombaça, Tanzânia e Centauro, implantados em parcelas de $9 \mathrm{~m}^{2}$ ( $3 \mathrm{~m} \mathrm{x} 3 \mathrm{~m}$ ) no ano de 1999. As doses de nitrogênio testadas foram: 50,75 e $100 \mathrm{~kg} / \mathrm{ha}$ de $\mathrm{N}$ após cada corte, na forma de sulfato de amônio, com e sem irrigação.

Antes do início do experimento, foi realizada a análise do solo, amostrado a $0-20 \mathrm{~cm}$ de profundidade, que apresentou as seguintes características: $\mathrm{pH}=5,0$; $\mathrm{Ca}^{++}=24 \mathrm{mmol}_{\mathrm{c}} / \mathrm{dm}^{3} ; \mathrm{P}=27 \mathrm{mg} / \mathrm{dm}^{3} ; \mathrm{Mg}^{++}=1$ $\mathrm{mmol}_{\mathrm{c}} / \mathrm{dm}^{3} ; \mathrm{K}^{+}=0,7 \mathrm{mmol}_{\mathrm{c}} / \mathrm{dm}^{3} ; \mathrm{Al}^{+++}=0 \mathrm{mmol}_{\mathrm{c}} /$ $\mathrm{dm}^{3} ; \mathrm{H}+\mathrm{Al}=22 \mathrm{mmol}_{\mathrm{c}} / \mathrm{dm}^{3} ; \mathrm{MO}=31 \mathrm{~g} / \mathrm{dm}^{3}, \mathrm{SB}=$ $25,9 \mathrm{mmol}_{\mathrm{c}} / \mathrm{dm}^{3} ; \mathrm{CTC}=47,9 \mathrm{mmol}_{\mathrm{c}} / \mathrm{dm}^{3} \mathrm{e} \mathrm{V} \%=54$. Realizou-se uma calagem, com aplicação de $0,8 \mathrm{t} / \mathrm{ha}$ de calcário dolomítico com PRNT de $85 \%$ e adubação em todas as parcelas com $100 \mathrm{~kg} / \mathrm{ha}$ de $\mathrm{P}_{2} \mathrm{O}_{5}$ e $60 \mathrm{~kg} / \mathrm{ha}$ de $\mathrm{K}_{2} \mathrm{O}$, nas formas de superfosfato simples e cloreto de potássio, respectivamente.

Os dados climáticos de precipitação pluviométrica, temperatura, umidade relativa, evapotranspiração e balanço hídrico registrados durante o período experimental foram coletados na estação meteorológica, localizada a $300 \mathrm{~m}$ do local do experimento, e estão apresentados na Tabela 1 .

Em 06/09/00, os cinco cultivares de Panicum maximum foram rebaixados a $5 \mathrm{~cm}$ do solo, aplicandose os tratamentos. Para as avaliações, a forragem foi cortada manualmente a $25-30 \mathrm{~cm}$ do solo, numa área de $2 \mathrm{~m}^{2}$, utilizando-se um cutelo (ferramenta de cortar arroz). As colheitas foram realizadas com intervalos de 30 a 35 dias, na época chuvosa, e, na época seca, de 40 a 45 dias.

O material coletado foi acondicionado em saco de polietileno identificado e enviado para o laboratório, onde foi pesado, para determinação da produção total. As amostras foram retiradas, pesadas e levadas estufa de ventilação forçada, a $65^{\circ} \mathrm{C}$ por 72 horas, para determinação da matéria seca parcial, e, em seguida, foram armazenadas. Posteriormente, foram processadas em moinho tipo Willey com peneira de crivo de $1 \mathrm{~mm}$, acondicionado-se o material em sacos de polietileno devidamente identificados. Foram analisados os teores de matéria seca (MS), conforme a metodologia descrita por Silva (1990).

Após a coleta das amostras, a bordadura de cada parcela foi cortada mecanicamente com roçadeira costal, retirando-se o material da área e as parcelas adubadas com nitrogênio, de acordo com cada tratamento. Aplicaram-se também, após cada corte, $30 \mathrm{~kg} /$ ha de $\mathrm{K}_{2} \mathrm{O}$ na forma de cloreto de potássio.

O sistema de irrigação adotado foi o convencional, utilizando-se tubos de aço zincado de engate rápido com diâmetro de 3 polegadas, com bocal de 5,0 $\mathrm{mm}$. O sistema fornecia uma lâmina de água de $6,0 \mathrm{~mm} / \mathrm{h}$, operando em uma pressão de serviço de 4,0 atm. Antes do experimento, foi realizada irrigação por aproximadamente, duas horas, para se uniformizar o solo, deixando-o na capacidade de campo.

As doses de nitrogênio e de potássio aplicadas após cada corte foram reduzidas pela metade durante os meses de maio, junho e agosto, para os tratamentos irrigados, em decorrência das menores taxas de crescimento dos cultivares neste período. Na ausência de irrigação, a redução das doses de nitrogênio e de potássio se deu apenas no mês de maio, enquanto, nos meses de junho, agosto e setembro, não se aplicaram estes nutrientes, em razão da baixa precipitação ocorrida nestes meses (Tabela 1 ).

Os dados de produção de massa de forragem total anual, para as estações seca e chuvosa, foram submetidos à análise de variância, obtendo-se médias comparadas pelo teste Tukey, a 5\% de probabilidade. Para a análise dos resultados, foi utilizado o programa estatístico ESTAT - Sistema para Análises Estatísticas (versão 2.0).

$\mathrm{Na}$ análise estatística, considerou-se a produção média de massa de forragem, cujos cortes ocorreram nos dias 11/10/00, 16/11/00, 16/12/00, 22/01/01,22/02/ 01 e 28/03/01, para a época chuvosa, e, para a época seca, nos dias 09/05/01, 20/06/01 e 06/08/01, no tratamento sem irrigação, enquanto, no tratamento com irrigação, realizou-se um corte a mais, no dia 18/09/01. 
Tabela 1 - Temperatura, umidade relativa, evapotranspiração, precipitação e balanço hídrico, por decêndios, ocorridos durante o período experimental (setembro de 2000 a setembro de 2001)

Table 1 - Temperature, relative humidity, evapotranspiration, rainfall and water balance, for a set of ten, during the experimental period (September/00 to September/01)

\begin{tabular}{|c|c|c|c|c|c|c|c|c|}
\hline \multirow[t]{2}{*}{$\begin{array}{l}\text { Meses/Ano } \\
\text { Month/Year }\end{array}$} & \multicolumn{2}{|c|}{$\begin{array}{c}\text { Decêndio } \\
\text { Space of ten days }\end{array}$} & \multicolumn{2}{|c|}{$\begin{array}{c}\text { Temperatura }\left({ }^{\circ} \mathrm{C}\right) \\
\text { Temperature }\end{array}$} & \multirow{2}{*}{$\begin{array}{c}\text { Umidade relativa } \\
\text { média }(\%) \\
\text { Average relative } \\
\quad \text { humidity }\end{array}$} & \multirow{2}{*}{$\begin{array}{c}\text { Evapotr. } \\
\text { TCA }(\mathrm{mm}) \\
\text { Evapotr. } \\
\text { Class A Pan }(\mathrm{mm})\end{array}$} & \multirow[t]{2}{*}{$\begin{array}{l}\text { Chuva (mm) } \\
\text { Rainfall }(\mathrm{mm})\end{array}$} & \multirow{2}{*}{$\begin{array}{c}\text { Balanço } \\
\text { hídrico } \\
\text { mensal }(\mathrm{mm}) \\
\text { Monthly water } \\
\text { balance }(\mathrm{mm})\end{array}$} \\
\hline & & $\begin{array}{l}\text { Máxima } \\
\text { Maximum }\end{array}$ & $\begin{array}{l}\text { Mínima } \\
\text { Minimum }\end{array}$ & $\begin{array}{l}\text { Média } \\
\text { Mean }\end{array}$ & & & & \\
\hline & 1 & 27,6 & 17,8 & 22,7 & 75,6 & 30,3 & 56,8 & \\
\hline SET/00 & 2 & 31,9 & 20,5 & 26,2 & 69,0 & 39,6 & 76,3 & 22,2 \\
\hline \multirow[t]{2}{*}{ September $/ 00$} & 3 & 29,9 & 20,9 & 25,4 & 60,9 & 46,1 & 5,1 & \\
\hline & 1 & 33,5 & 20,4 & 26,5 & 56,3 & 44,9 & 13,0 & \\
\hline OUT/00 & 2 & 37,1 & 22,4 & 29,2 & 51,5 & 51,5 & 4,9 & $-101,2$ \\
\hline \multirow[t]{2}{*}{ October/00 } & 3 & 34,1 & 21,7 & 27,2 & 61,0 & 43,7 & 21,0 & \\
\hline & 1 & 34,2 & 22,6 & 28,1 & 56,6 & 59,0 & 0 & \\
\hline NOV/00 & 2 & 31,2 & 21,0 & 25,6 & 71,0 & 38,7 & 75,2 & $-105,6$ \\
\hline \multirow{2}{*}{ November $/ 00$} & 3 & 32,9 & 21,5 & 26,2 & 70,9 & 48,4 & 29,6 & \\
\hline & 1 & 32,5 & 21,5 & 26,4 & 69,1 & 45,7 & 41,4 & \\
\hline DEZ/00 & 2 & 27,9 & 20,4 & 23,7 & 78,1 & 36,8 & 108,3 & 105,4 \\
\hline \multirow[t]{2}{*}{ December/00 } & 3 & 33,0 & 21,6 & 26,4 & 74,7 & 55,1 & 93,3 & \\
\hline & 1 & 32,4 & 22,3 & 26,4 & 73,9 & 41,3 & 33,9 & \\
\hline JAN/01 & 2 & 32,6 & 21,6 & 26,7 & 67,5 & 37,0 & 13,6 & 80,9 \\
\hline \multirow[t]{2}{*}{ January/01 } & 3 & 32,6 & 21,9 & 26,6 & 74,2 & 45,9 & 157,6 & \\
\hline & 1 & 33,3 & 22,5 & 27,0 & 75,5 & 42,1 & 56,7 & \\
\hline FEV/01 & 2 & 31,8 & 21,7 & 25,8 & 78,5 & 37,9 & 70,5 & 52,3 \\
\hline \multirow{2}{*}{ February/01 } & 3 & 32,7 & 21,6 & 26,4 & 73,5 & 25,7 & 30,8 & \\
\hline & 1 & 32,6 & 21,8 & 26,2 & 76,4 & 37,2 & 149,7 & \\
\hline MAR/01 & 2 & 32,2 & 22,4 & 26,7 & 74,9 & 43,8 & 5,8 & 42,7 \\
\hline \multirow[t]{2}{*}{ March/01 } & 3 & 33,0 & 21,2 & 26,6 & 70,8 & 40,6 & 8,8 & \\
\hline & 1 & 32,7 & 21,5 & 26,4 & 73,3 & 36,1 & 33,0 & \\
\hline $\mathrm{ABR} / 01$ & 2 & 33,7 & 21,5 & 27,5 & 56,8 & 65,7 & 0 & $-60,4$ \\
\hline \multirow[t]{2}{*}{ April/01 } & 3 & 32,1 & 21,3 & 26,3 & 63,4 & 36,4 & 44,8 & \\
\hline & 1 & 28,9 & 15,4 & 22,2 & 61,5 & 37,3 & 0 & \\
\hline MAI/01 & 2 & 24,6 & 14,5 & 19,3 & 74,3 & 21,1 & 58,0 & 22,5 \\
\hline \multirow[t]{2}{*}{ May/01 } & 3 & 27,6 & 18,1 & 22,1 & 76,9 & 23,1 & 46,0 & \\
\hline & 1 & 29,4 & 18,0 & 23,5 & 68,2 & 26,0 & 14,3 & \\
\hline JUN/01 & 2 & 24,6 & 14,7 & 19,5 & 69,9 & 27,1 & 22,0 & 3,5 \\
\hline \multirow[t]{2}{*}{ June/01 } & 3 & 23,9 & 11,1 & 17,0 & 69,5 & 21,4 & 42,0 & \\
\hline & 1 & 30,1 & 15,7 & 22,6 & 56,8 & 34,8 & 0 & \\
\hline JUL/01 & 2 & 29,2 & 15,4 & 21,8 & 61,9 & 31,1 & 9,2 & $-78,4$ \\
\hline \multirow[t]{2}{*}{ July $/ 01$} & 3 & 28,0 & 15,6 & 21,1 & 68,0 & 30,9 & 9,9 & \\
\hline & 1 & 31,2 & 16,3 & 23,7 & 44,2 & 36,4 & 0 & \\
\hline $\mathrm{AGO} / 01$ & 2 & 31,4 & 17,3 & 24,4 & 39,7 & 48,7 & 0 & $-105,0$ \\
\hline \multirow[t]{2}{*}{ August/01 } & 3 & 31,1 & 18,5 & 23,5 & 65,3 & 36,7 & 16,8 & \\
\hline & 1 & 35,5 & 20,1 & 27,8 & 42,9 & 59,3 & 0 & \\
\hline SET/01 & 2 & 29,3 & 16,3 & 22,5 & 54,8 & 42,9 & 15,8 & $-81,2$ \\
\hline September $/ 01$ & 3 & 30,9 & 20,2 & 25,0 & 67,7 & 28,5 & 33,7 & \\
\hline
\end{tabular}

\section{Resultados e Discussão}

A produção de massa de forragem (PMF) obtida para os diferentes tratamentos, durante o período experimental, está apresentada na Tabela 2.

Houve interação significativa para cultivares $\mathrm{x}$ irrigação e cultivares $\mathrm{x}$ doses de nitrogênio. A presença de irrigação proporcionou as maiores produções para todos os cultivares estudados, com aumentos significativos na MF $(\mathrm{P}<0,05)$, em relação ao tratamento sem irrigação. Na presença de irrigação, o cultivar Mombaça apresentou a maior $\operatorname{PMF}(41,68 \mathrm{t} / \mathrm{ha})$ $(\mathrm{P}<0,05)$ em relação aos demais cultivares, que não diferiram estatisticamente entre si $(\mathrm{P}>0,05) \mathrm{e}$, na 
Tabela 2 - Produção de massa de forragem total (t/ha), durante o período experimental, para os diferentes tratamentos Table 2 - Dry matter yield (t/ha), during the experimental period, for the different treatments

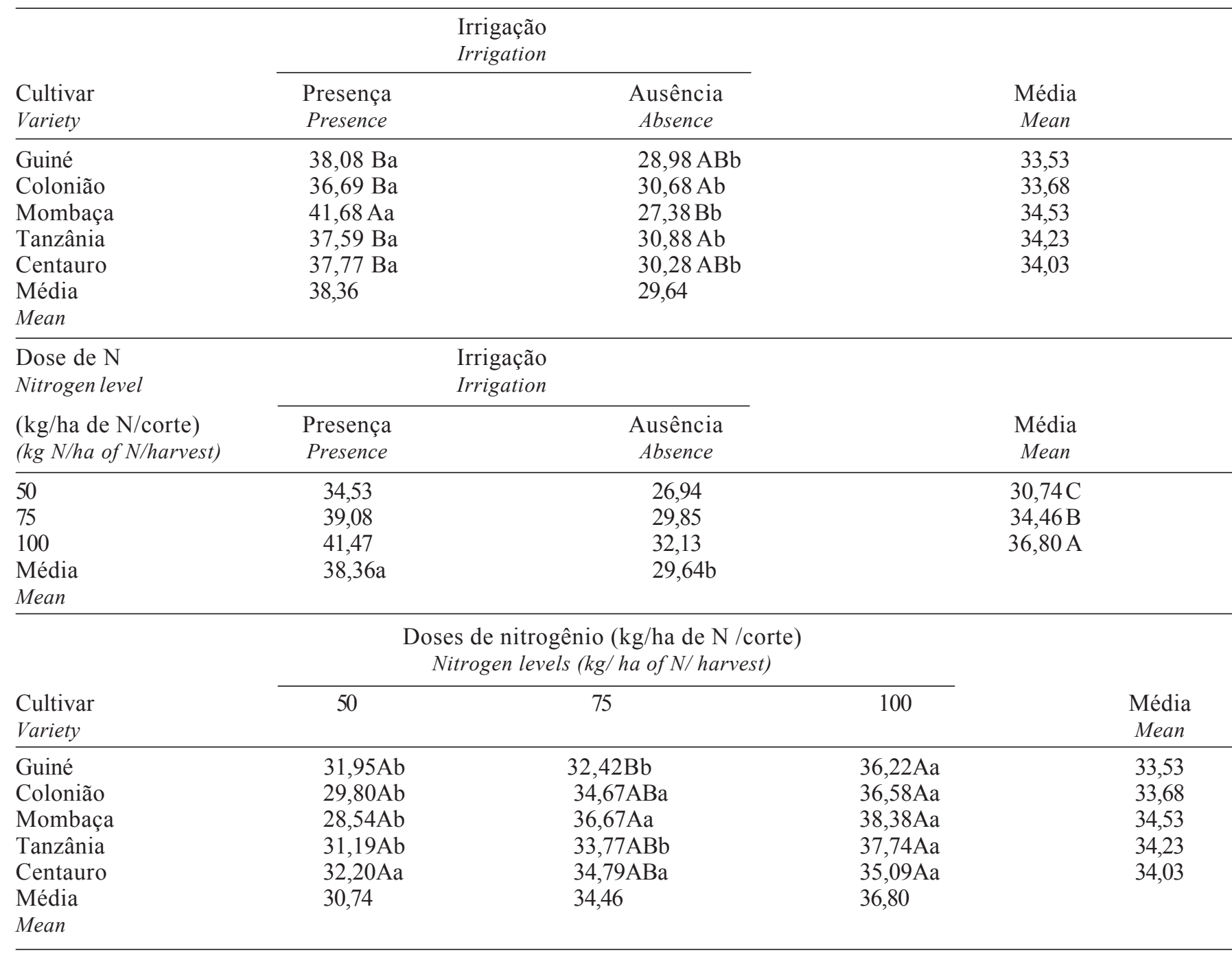

MMédias seguidas de diferentes letras minúsculas nas linhas e maiúsculas nas colunas diferem $(P<0,05)$ pelo teste Tukey. Means followed by different small letters within a row and capital letters within a column differ $(P<0.05)$ by Tukey test. $\mathrm{CV}=8,11$.

ausência, a menor PMF (27,38 t/ha); ou seja, a irrigação promoveu aumento de 14,3 t/ha de MF para este cultivar.

Não houve interação significativa doses de $\mathrm{N} \mathrm{x}$ irrigação. À medida que se elevaram as doses de N, houve acréscimo significativo na PMF, que foi, em média, de 30,74; 34,46 e 36,80 t/ha, para as doses de 50,75 e $100 \mathrm{~kg}$ de N/ha, respectivamente. A irrigação promoveu aumento médio da PMF de 29,4\% em relação à produção obtida sem irrigação. Resultados semelhantes foram registrados por Aveiro et al. (1991), em que a irrigação proporcionou maior PMF em capim-elefante.

Houve interação significativa doses de $\mathrm{N} x$ cultivares. Entre os cultivares, com as doses de 50 e
$100 \mathrm{~kg} / \mathrm{ha}$ de $\mathrm{N}$, as produções de MF não diferiram entre si $(\mathrm{P}>0,05)$. Quando se aplicaram $75 \mathrm{~kg} / \mathrm{ha}$ de $\mathrm{N}$, o cultivar Mombaça diferiu $(\mathrm{P}<0,05)$ apenas do cultivar Guiné, ao passo que os demais cultivares apresentaram produções semelhantes entre si. Ghisi et al. (1989), trabalhando com seis cultivares de Panicum maximum recebendo 25 e $50 \mathrm{~kg} / \mathrm{ha}$ de $\mathrm{N}$, não observaram diferenças nas produções de MS. Do mesmo modo, Cecato et al. (1996), avaliando os capins Colonião, Tanzânia e Mombaça, não encontraram diferença significativa na produção de MS. O mesmo fato foi observado por Santos et al. (2003), ao analisarem a produção e o crescimento dos cultivares Mombaça e Tanzânia. Os cultivares Guiné e Tanzânia apresentaram maior PMF $(\mathrm{P}<0,05)$ quando se aplica- 
ram $100 \mathrm{~kg} /$ ha de $\mathrm{N}$, enquanto, nos cultivares Colonião e Mombaça, não se observou diferença na PMF $(\mathrm{P}>0,05)$ com as doses de 75 e $100 \mathrm{~kg} / \mathrm{ha}$ de N. O cultivar Centauro apresentou PMF semelhante $(\mathrm{P}>0,05)$ nas três doses de $\mathrm{N}$ estudadas.

Os dados de produção de $\mathrm{MF}$, em t/ha, para os diferentes tratamentos, durante a época chuvosa, que correspondeu aos cortes efetuados no período entre outubro/00 e março/01, encontram-se na Tabela 3. Para a época chuvosa, houve interação significativa cultivares $\mathrm{x}$ irrigação e cultivares $\mathrm{x}$ doses de N. A irrigação proporcionou maior $\mathrm{PMF}(\mathrm{P}<0,05)$ ao cultivar Mombaça, com 32,13 t/ha. Na ausência de irrigação, não houve diferença $(\mathrm{P}>0,05)$ entre os cultivares.
Benedetti et al. (2001) observaram, para o capimtanzânia irrigado, cortado aos 30 dias, produção de 5,7 t/ha de MV, enquanto, neste estudo, foi observada produção de 27,8 t/ha de $\mathrm{MF}$, no mesmo período. Quanto ao efeito da irrigação, observa-se que, para todos os cultivares estudados, sua presença promoveu acréscimos significativos $(\mathrm{P}<0,05)$ na $\mathrm{PMF}$.

A irrigação resultou em incremento de $2,5 \mathrm{t} /$ ha na PMF, para o cultivar Colonião, e de 10 t/ha, para o cultivar Mombaça, em relação à produção obtida sem irrigação, indicando que, nesta região, embora a temperatura e o fotoperíodo, nesta época do ano, sejam favoráveis ao crescimento da planta, normalmente ocorrem veranicos prejudicando seu desenvolvimento

Tabela 3 - Produção de massa de forragem total (t/ha), durante a época chuvosa (outubro/00 - março/01), nos diferentes tratamentos

Table 3 - Dry matter yield (t/ha), during the rainy season (October/00 - March/01), for the different treatments

\begin{tabular}{|c|c|c|c|c|c|}
\hline \multirow[b]{2}{*}{$\begin{array}{l}\text { Cultivar } \\
\text { Variety }\end{array}$} & \multicolumn{2}{|c|}{$\begin{array}{l}\text { Irrigação } \\
\text { Irrigation }\end{array}$} & & \multirow[b]{2}{*}{$\begin{array}{l}\text { Média } \\
\text { Mean }\end{array}$} & \\
\hline & $\begin{array}{l}\text { Presença } \\
\text { Presence }\end{array}$ & $\begin{array}{l}\text { Ausência } \\
\text { Absence }\end{array}$ & & & \\
\hline $\begin{array}{l}\text { Guiné } \\
\text { Colonião } \\
\text { Mombaça } \\
\text { Tanzânia } \\
\text { Centauro } \\
\text { Média } \\
\text { Mean }\end{array}$ & $\begin{array}{l}28,42 \mathrm{Ba} \\
27,24 \mathrm{Ba} \\
32,13 \mathrm{Aa} \\
27,80 \mathrm{Ba} \\
28,42 \mathrm{Ba} \\
28,80\end{array}$ & $\begin{array}{l}23,96 \mathrm{Ab} \\
24,80 \mathrm{Ab} \\
22,23 \mathrm{Ab} \\
24,43 \mathrm{Ab} \\
24,23 \mathrm{Ab} \\
23,93\end{array}$ & & $\begin{array}{l}26,19 \\
26,02 \\
27,18 \\
26,12 \\
26,32\end{array}$ & \\
\hline $\begin{array}{l}\text { Dose de } \mathrm{N} \\
\text { Nitrogen level }\end{array}$ & \multicolumn{2}{|c|}{$\begin{array}{l}\text { Irrigação } \\
\text { Irrigation }\end{array}$} & & & \\
\hline $\begin{array}{l}\text { ( } \mathrm{kg} / \mathrm{ha} \text { de } \mathrm{N} / \text { corte }) \\
\text { (kg N/ha of N/harvest) }\end{array}$ & $\begin{array}{l}\text { Presença } \\
\text { Presence }\end{array}$ & $\begin{array}{l}\text { Ausência } \\
\text { Absence }\end{array}$ & & $\begin{array}{l}\text { Média } \\
\text { Mean }\end{array}$ & \\
\hline $\begin{array}{l}50 \\
75 \\
100 \\
\text { Média } \\
\text { Mean }\end{array}$ & $\begin{array}{l}26,53 \\
29,49 \\
30,40 \\
28,80 \mathrm{a}\end{array}$ & $\begin{array}{l}21,62 \\
24,48 \\
25,70 \\
23,93 \mathrm{~b}\end{array}$ & & $\begin{array}{c}24,07 \mathrm{~B} \\
26,98 \mathrm{~A} \\
28,04 \mathrm{~A}\end{array}$ & \\
\hline & \multicolumn{3}{|c|}{$\begin{array}{l}\text { Doses de nitrogênio }(\mathrm{kg} / \mathrm{ha} \text { de } \mathrm{N} / \text { corte }) \\
\text { Nitrogen levels }(\mathrm{kg} / \text { ha of } \mathrm{N} / \text { harvest })\end{array}$} & & \\
\hline $\begin{array}{l}\text { Cultivar } \\
\text { Variety }\end{array}$ & 50 & 75 & 100 & & $\begin{array}{l}\text { Média } \\
\text { Mean }\end{array}$ \\
\hline $\begin{array}{l}\text { Guiné } \\
\text { Colonião } \\
\text { Mombaça } \\
\text { Tanzânia } \\
\text { Centauro } \\
\text { Média } \\
\text { Mean }\end{array}$ & $\begin{array}{l}25,27 \mathrm{Aa} \\
23,44 \mathrm{Ab} \\
22,37 \mathrm{Ab} \\
24,28 \mathrm{Ab} \\
25,00 \mathrm{Aa} \\
24,07\end{array}$ & $\begin{array}{l}25,93 \mathrm{Ba} \\
26,60 \mathrm{ABa} \\
29,50 \mathrm{Aa} \\
25,52 \mathrm{Bb} \\
27,38 \mathrm{ABa} \\
26,98\end{array}$ & $\begin{array}{l}27,38 \mathrm{Aa} \\
28,03 \mathrm{Aa} \\
29,67 \mathrm{Aa} \\
28,55 \mathrm{Aa} \\
26,60 \mathrm{Aa} \\
28,04\end{array}$ & & $\begin{array}{l}26,19 \\
26,02 \\
27,18 \\
26,12 \\
26,32\end{array}$ \\
\hline
\end{tabular}

Médias seguidas de diferentes letras minúsculas nas linhas e maiúsculas nas colunas diferem $(P<0,05)$ pelo teste Tukey. Means followed by different small letters within a row and capital letters within a column differ $(P<0.05)$ by Tukey test. CV $=9,51$. 
(Tabela 1). Assim, o fornecimento de água por meio de irrigação pode ser uma prática para antecipação da estação de crescimento das plantas forrageiras.

Observou-se que, com as doses de 50 e $100 \mathrm{~kg} / \mathrm{ha}$ de $\mathrm{N}$, não houve diferença significativa $(\mathrm{P}>0,05)$ na PMF entre os cultivares. No entanto, quando foram aplicados $75 \mathrm{~kg} /$ ha de $\mathrm{N}$ após cada corte, houve diferença $(\mathrm{P}<0,05)$ na $\mathrm{PMF}$ para o capim-Mombaça, em relação aos cultivares Guiné e Tanzânia.

Consta na Tabela 4 a produção de MF (t/ha) durante a época seca, que compreendeu os cortes realizados nos meses de maio, junho, agosto e setembro, para o tratamento com irrigação, e nos meses de maio, junho e agosto, para o tratamento sem irrigação.
Para a época seca, houve interação significativa somente entre doses de $\mathrm{N} x$ irrigação, que promoveu maior $\mathrm{PMF}(\mathrm{P}<0,05)$, proporcionando um corte a mais nesta estação em relação aos tratamentos sem irrigação. Na presença de irrigação, as doses $\mathrm{N}$ proporcionaram diferença significativa na $\mathrm{PMF}(\mathrm{P}<0,05)$. À medida que se aumentou a dose de $\mathrm{N}$, houve acréscimo na PMF que foi de 11,$08 ; 9,58$ e 7,97 t/ha. Na ausência de irrigação, os resultados obtidos com a dose de $100 \mathrm{~kg} / \mathrm{ha}$ de $\mathrm{N}(\mathrm{P}<0,05)$ diferiram daqueles encontrados com $50 \mathrm{~kg} / \mathrm{ha}$ de N. Resultados semelhantes foram observados em capim-elefante por Andrade et al. (2002), que obtiveram aumento significativo na PMF de 13,6 para 19,2 t/ha, com a presen-

Tabela 4 - Produção de massa de forragem total (t/ha), durante a época seca (abril/01 -setembro/01), para os diferentes tratamentos

Table 4 - Dry matter yield (t/ha), during the dry season (April/01 - September/01), for the different treatments

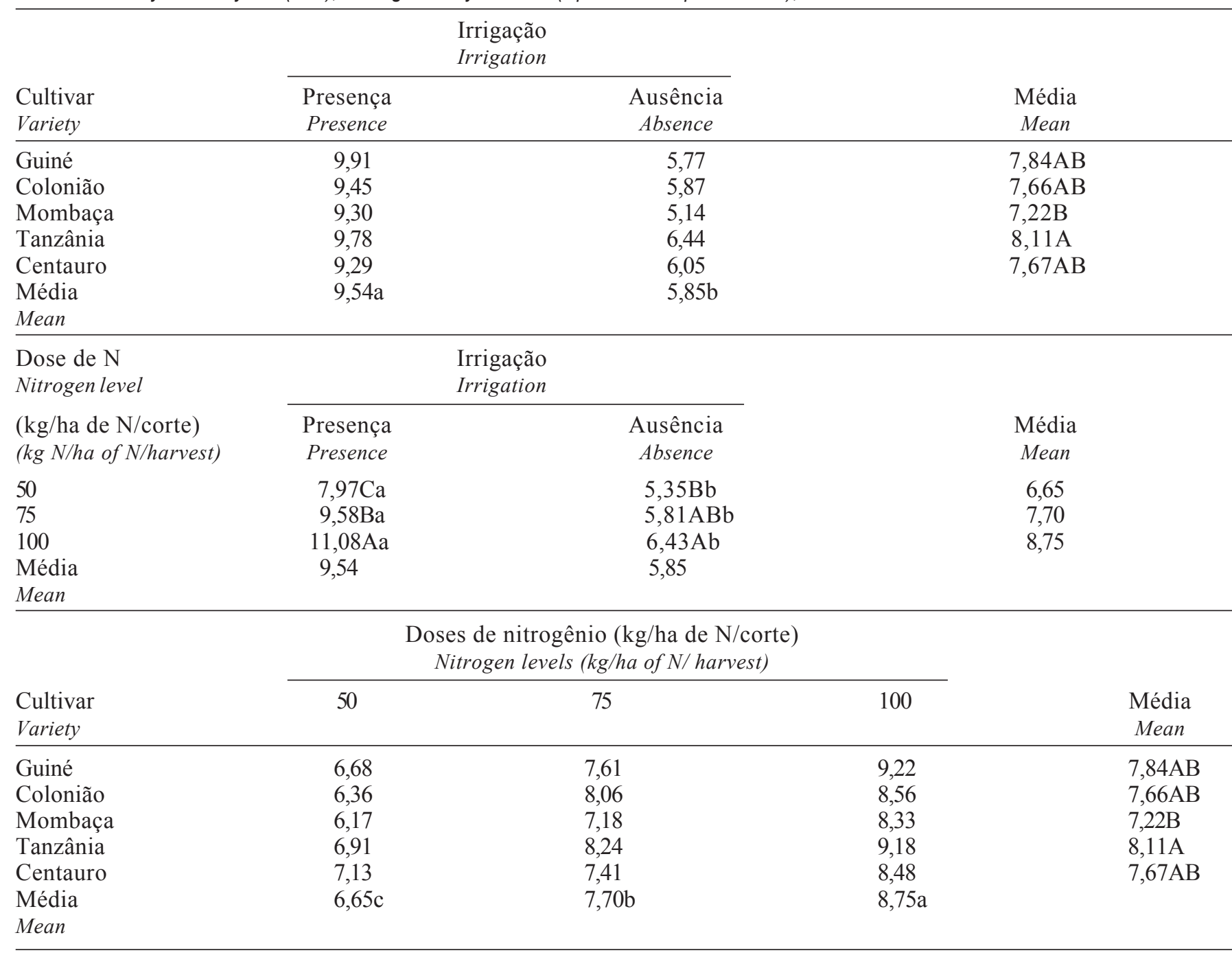

Médias seguidas de diferentes letras minúsculas nas linhas e maiúsculas nas colunas diferem $(P<0,05)$ pelo teste Tukey. Means followed by different small letters within a row and capital letters within a column differ $(P<0.05)$ by Tukey test. $\mathrm{CV}=13,33$ 
ça de irrigação, e acréscimo de $131 \%$ na disponibilidade de MF entre a menor e a maior dose de adubação nitrogenada (100 e $400 \mathrm{~kg} / \mathrm{ha}$ de $\mathrm{N}$ ).

Houve acréscimo significativo na PMF com o aumento das doses de nitrogênio, com médias de 8,75; 7,70 e $6,65 \mathrm{t} / \mathrm{ha}$, para 100,75 e $50 \mathrm{~kg} / \mathrm{ha}$ de $\mathrm{N}$, respectivamente. Entre os cultivares, apenas o Tanzânia e o Mombaça apresentaram diferença $(\mathrm{P}<0,05)$.

Observou-se queda acentuada da PMF na estação seca em relação à chuvosa, que foi, em média, de 28,80 para 9,54 t/ha de MF, no tratamento com irrigação, e de 23,93 para 5,85 t/ha de $\mathrm{MF}$, sem irrigação, mesmo utilizando técnicas de manejo, como adubação nitrogenada e irrigação, o que evidencia a importância do fotoperíodo e da temperatura para o desenvolvimento da planta forrageira. Estes resultados de estacionalidade de produção corroboram os descritos por outros autores (Alvim et al., 1986; Müller, 2000; Marcelino et al., 2003), que observaram redução significativa na produção de MF das gramíneas, no inverno, mesmo com irrigação, em razão das baixas temperaturas e dos dias curtos neste período.

Constam, nas Figuras 1, 2 e 3, as curvas de MF durante o período experimental para os cultivares estudados, com as doses de 50, 75 e $100 \mathrm{~kg} / \mathrm{ha}$ de $\mathrm{N}$ por corte, respectivamente.

Verificou-se comportamento semelhante para as três doses de N; a irrigação promoveu aumento na PMF nos meses de outubro, novembro e dezembro, em relação ao tratamento sem irrigação. $\mathrm{O}$ aumento da PMF obtido no mês de novembro pode ter sido resultante da irrigação, da temperatura favorável ou de outros fatores, até mesmo fisiológicos. Constatouse balanço hídrico negativo de 110,3 mm (Tabela 1), o que, provavelmente prejudicou o desenvolvimento das forrageiras no tratamento sem irrigação. O pico de produção ocorrido no mês de novembro também foi observado por Penati et al. (2001), no mesmo período, quando a lotação animal passou de 6 para $9 \mathrm{UA} / \mathrm{ha}$, reduzindo no mês seguinte para $5 \mathrm{UA} / \mathrm{ha}$, em pastagem irrigada de capim-tanzânia.

Do mês de janeiro até o corte realizado no mês de junho, as produções de MF foram semelhantes às do tratamento sem irrigação. Conforme a Tabela 1, no período de dezembro a junho, exceto o mês de abril, a precipitação foi maior que a evapotranspiração, ou seja, houve balanço hídrico positivo, mantendo a umidade no solo e dando condições ao desenvolvimento das forrageiras, no tratamento sem irrigação.

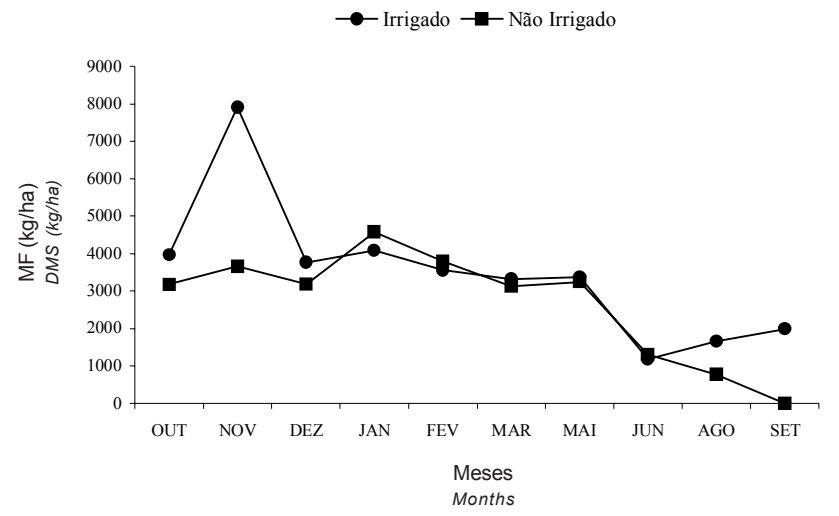

Figura 1 - Massas de forragem (kg/ha) obtidas com aplicação de $50 \mathrm{~kg} / \mathrm{ha}$ de $\mathrm{N}$ após cada corte, no período de outubro de 2000 a setembro de 2001. Média de cinco cultivares.

Figure 1 - Dry matter yield ( $\mathrm{kg} / \mathrm{ha}$ ), with application of $50 \mathrm{~kg} / \mathrm{ha}$ of $N$ after each harvest, in the period from October 2000 to September 2001. Mean of five varieties.

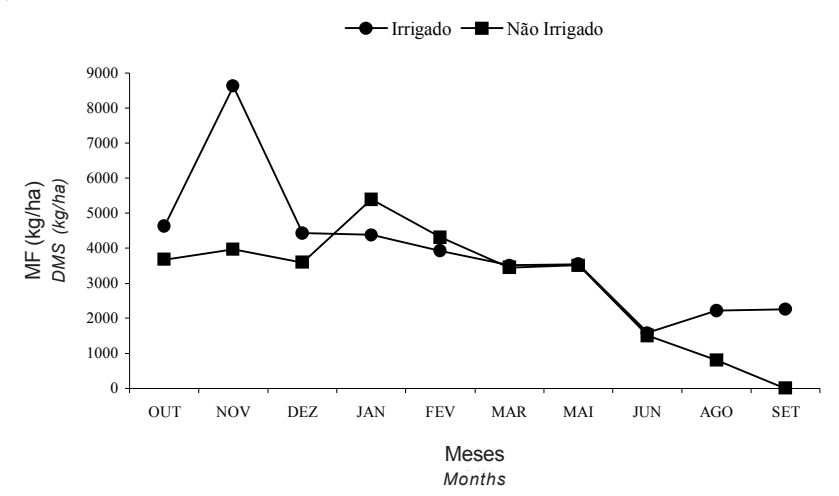

Figura 2 - Massas de forragem (kg/ha) obtidas com aplicação de $75 \mathrm{~kg} / \mathrm{ha}$ de $\mathrm{N}$ após cada corte, no período de outubro de 2000 a setembro de 2001. Média de cinco cultivares.

Figure 2 - Dry matter yield (kg/ha), with application of $75 \mathrm{~kg} / \mathrm{ha}$ of $N$ after each harvest, in the period from October 2000 to September 2001. Mean of five varieties.

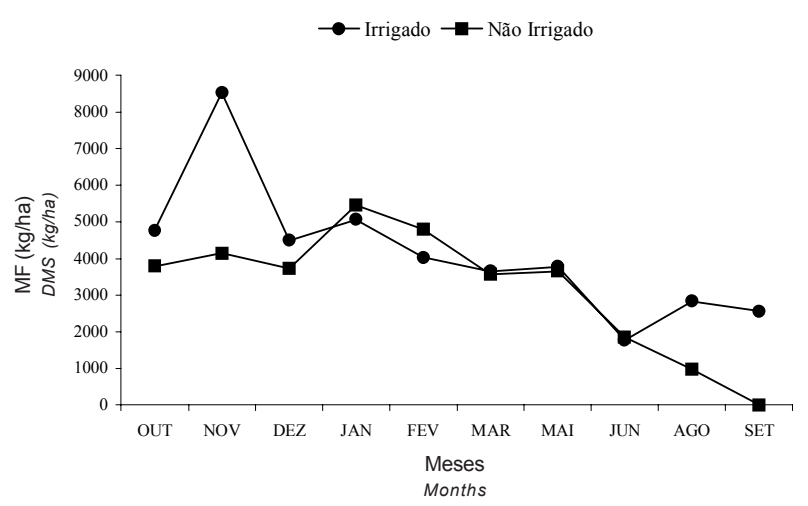

Figura 3 - Massas de forragem (kg/ha) obtidas com aplicação de $100 \mathrm{~kg} / \mathrm{ha}$ de $\mathrm{N}$ após cada corte, no período de outubro de 2000 a novembro de 2001. Média de cinco cultivares.

Figure 3 - Dry matter yield ( $\mathrm{kg} / \mathrm{ha}$ ), with application of $100 \mathrm{~kg} / \mathrm{ha}$ of $N$ after each harvest, in the period from October 2000 to September 2001. Mean of five varieties. 
A queda acentuada de PMF no mês de junho pode ser atribuída à queda da temperatura média, associada à diminuição do fotoperíodo. Segundo Bryan \& Sharpe (1965), a temperatura ambiente crítica para o crescimento de forrageiras tropicais é em torno de $15^{\circ} \mathrm{C}$. Após este período, houve aumento na PMF nos meses de agosto, setembro, outubro e novembro com o aumento da temperatura média registrada no período e com o suprimento de água por meio da irrigação (Tabela 1).

Na ausência de irrigação, houve queda progressiva na produção a partir do mês de junho, de modo que, em setembro, não foi possível a colheita, em virtude da baixa produção de massa de forragem destes tratamentos.

Verificou-se efeito positivo da irrigação sobre a PMF a partir do final da estação seca, quando as temperaturas mínimas começaram a se elevar e o fotoperíodo não foi mais limitante; ou seja, com a irrigação, foi possível antecipar o início da estação de crescimento das forrageiras, elevando a PMF a partir do mês de agosto, com produções médias de 1 a 2 t/ ha de MF, com a dose de $75 \mathrm{~kg} / \mathrm{ha}$ de $\mathrm{N}$ por corte (Figura 2), e de até $3 \mathrm{t} / \mathrm{ha}$ de MF, com $100 \mathrm{~kg} / \mathrm{ha}$ de N por corte (Figura 3).

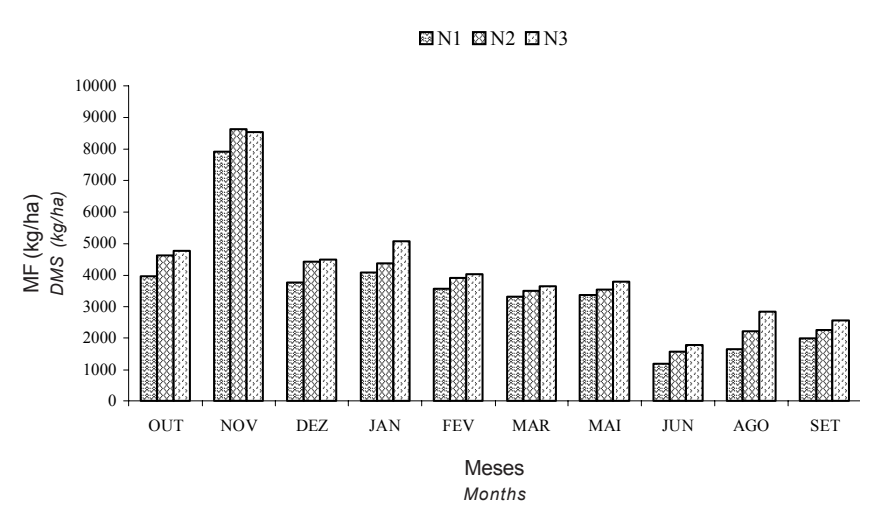

Figura 4 - Massas de forragem (kg/ha) obtidas de cultivares de Panicum maximum, em função das doses de nitrogênio na presença de irrigação. Média de cinco cultivares.

Figure 4 - Dry matter yield ( $\mathrm{kg} / \mathrm{ha}$ ) of Panicum maximum varieties, as affected by the nitrogen levels, treatment with irrigation. Mean of five varieties.
Nas Figuras 4 e 5, observa-se mostram o comportamento da PMF, em função das doses de $\mathrm{N}$ estudadas. Na presença de irrigação (Figura 4), o corte realizado no mês de novembro apresentou as maiores produções, com aproximadamente $8 \mathrm{t} / \mathrm{ha}$ de $\mathrm{MF}$, para a dose de $50 \mathrm{~kg} / \mathrm{ha}$ de $\mathrm{N}$ por corte, e $9 \mathrm{t} / \mathrm{ha}$ de $\mathrm{MF}$, para as doses de 75 e $100 \mathrm{~kg} / \mathrm{ha}$ de $\mathrm{N}$ por corte. As menores produções foram registradas no mês de junho, para as três doses de $\mathrm{N}$ aplicadas, oscilando entre 1 e $2 \mathrm{t} / \mathrm{ha}$ de MF. A partir daí, houve aumento na PMF, provavelmente, em virtude das melhores condições climáticas neste período.

$\mathrm{Na}$ ausência de irrigação (Figura 5), a PMF foi semelhante entre os meses de outubro e maio, com produções entre 3 e 4 t de $\mathrm{MF} / \mathrm{ha} /$ corte. No mês de janeiro, observou-se a maior produção para as três doses de $\mathrm{N}$ estudadas, que ficou entre 4,5 t de $\mathrm{MF} / \mathrm{ha}$, para a menor dose de $\mathrm{N}$, e 5,5 t de $\mathrm{MF} / \mathrm{ha}$, para as doses de 75 e $100 \mathrm{~kg}$ de N/ha/corte. Houve declínio na PMF a partir de junho, até o mês de setembro. Após este mês, a PMF aumentou, em decorrência do início do período chuvoso, quando as plantas encontraram condições favoráveis para seu desenvolvimento, como temperatura, fotoperíodo e água.

圈N1 图N2 回N3

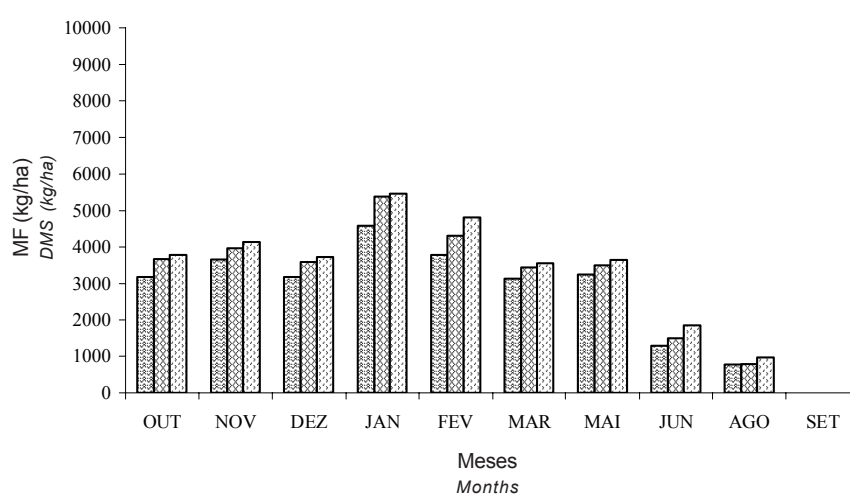

Figura 5 - Massas de forragem (kg/ha) obtidas de cultivares de Panicum maximum em função das doses de nitrogênio, na ausência de irrigação. Média de cinco cultivares.

Figure 5 - Dry matter yield ( $\mathrm{kg} / \mathrm{ha}$ ) of Panicum maximum varieties, as affected by the nitrogen levels, treatment without irrigation. Mean of five varieties. 


\section{Conclusões}

A irrigação proporcionou maior produção de massa de forragem nos cultivares de Panicum maximum.

Entre os cultivares, o Mombaça apresentou maior produção de massa de forragem quando irrigado.

Independentemente da irrigação, os cultivares estudados responderam à aplicação de nitrogênio.

\section{Literatura Citada}

ALVIM, M.J.; BOTREL, M.A.; NOVELLY, P.E. Produção de gramíneas tropicais e temperadas, irrigadas na época da seca. Revista da Sociedade Brasileira de Zootecnia, v.15, n. 5, p.384-92, 1986.

ANDRADE, A.C.; FONSECA, D.M.; LOPES, R.S. Disponibilidade de matéria seca e composição química do capimelefante Napier sob adubação e irrigação. In: REUNIÃO ANUAL DA SOCIEDADE BRASILEIRA DE ZOOTECNIA, 39., 2002, Recife. Anais... Recife: Sociedade Brasileira de Zootecnia, 2002. CD-ROM.

ARONOVICH, S; ROCHA, G.L. Gramíneas e leguminosas forrageiras de importância no Brasil Central Pecuário. Informe Agropecuário, v.11, p.139, 1985.

ARONOVICH, S. O capim colonião e outros cultivares de Panicum maximum (Jacq.): introdução e evolução do uso no Brasil. In: SIMPÓSIO SOBRE MANEJO DA PASTAGEM, 12., 1995, Piracicaba. Anais...Piracicaba: Fundação de Estudos Agrários Luiz de Queiroz, 1995. p.1-20.

AVEIRO, A.R.; SIEWERDT, L.; SILVEIRA JR., P. Capimelefante: efeitos da irrigação e das adubações mineral e orgânica. I. Teor e produção total de matéria seca. Revista da Sociedade Brasileira de Zootecnia, v.20, n.4, p.339-347, 1991.

BENEDETTI, E.; COLMANETTI, A.L.; DEMETRIO, R.A. Produção e composição bromatológica do capim Panicum maximum Jacq. cv. Tanzânia irrigado em solo de cerrado. Veterinária Notícias, v.27, n.2, p.123-128, 2001.

BRYAN, W.W.; SHARPE, J.P. The effect of urea and cutting treatments on the production of Pangola grass in southeastern Queensland. Australian Journal of Experimental Agriculture and Animal Hubandry, n.5, p.433-441, 1965.

CECATO, U.; BARBOSA, M.A.A.F.; SAKAGUTI, E.S. et al. Avaliação de cultivares de Panicum maximum Jacq. In: REUNIÃO ANUAL DA SOCIEDADE BRASILEIRA DE ZOOTECNIA, 33., 1996, Fortaleza. Anais... Fortaleza: Sociedade Brasileira de Zootecnia, 1996. p.109-111.

CORSI, M.; NUSSIO, L.G. Manejo do capim-elefante: correção e adubação do solo. In: SIMPÓSIO SOBRE MANEJO DA PASTAGeM, 10., 1993, Piracicaba. Anais... Piracicaba: Fundação de Estudos Agrários Luiz de Queiroz, 1993. p.87-116.

FAVORETTO, V.; RODRIGUES, L.R.A.; TUPINAMBÁ, C.F. Estudo do nitrogênio na produção e composição bromatológica do capim-colonião e seus aspectos econômicos. Científica, v.16, n.1, p.71-78, 1988.

GHISI, O.M.; ALMEIDA, A.R.P.; ALCÂNTARA, V.B.G. Avaliação agronômica de seis cultivares de Panicum maximum Jacq. sob três níveis de adubação. Boletim da Indústria Animal, v.46, n.1, p.1-15, 1989.
GUELFI FILHO, H. Efeito da irrigação sobre a produtividade do capim-elefante (Pennisetum purpureum Schum.). Piracicaba: Escola Superior de Agricultura "Luiz de Queiroz", 1972.77p. Tese (Doutorado em Fitotecnia) - Escola Superior de Agricultura “Luiz de Queiroz”,1972.

HERNANDEZ, F.B.T.; LEMOS FILHO, M.A.F.; BUZETTI, S. Software HIDRISA e o balanço hídrico de Ilha Solteira. Ilha Solteira: UNESP/FEIS/Área de Hidráulica e Irrigação, 1995. 45p. (Série irrigação, 1)

JANK, L. Melhoramento e seleção de variedades de Panicum maximum. In: SIMPÓSIO SOBRE MANEJO DA PASTAGEM, 12., 1995, Piracicaba. Anais... Piracicaba: Fundação de Estudos Agrários “Luiz de Queiroz”, 1995. p.21-58.

MARCELINO, K.R.A.; VILELA, L.; LEITE, G.G. Manejo da adubação nitrogenada de tensões hídricas sobre a produção da matéria seca e índice de área foliar de tifton 85 cultivado no cerrado. Revista Brasileira de Zootecnia, v.32, n.2, p.268-275, 2003.

MÜLLER, M.S. Desempenho de Panicum maximum (cv. Mombaça) em pastejo rotacionado, sob sistema de irrigação por pivô central, na região do cerrado. Piracicaba: Escola Superior de Agricultura "Luiz de Queiroz", 2000. 101p. Dissertação (Mestrado em Fitotecnia) - Escola Superior de Agricultura "Luiz de Queiroz", 2000.

PEDREIRA, J.V.S. Crescimento estacional dos capins colonião (Panicum maximum Jacq.), gordura (Melinis minutiflora Pal de Beauv.), jaraguá (Hyparrhenia rufa (Ness) Stapf.) e pangola de Taiwan A-24. Boletim da Indústria Animal, v.30, n.1, p.59-145, 1973.

PENATI, M.A.; MAYA, F.L.A.; CORSI, M. Resposta da taxa de lotação animal em pastagem irrigada de capim tanzânia manejada em três níveis de massa de forragem pós-pastejo. In: REUNIÃO ANUAL DA SOCIEDADE BRASILEIRA DE ZOOTECNIA, 38., 2001, Piracicaba. Anais... Piracicaba: Sociedade Brasileira de Zootecnia, 2001. p.346-348.

PINHEIRO, V.D. Viabilidade econômica da irrigação de pastagem de capim Tanzânia em diferentes regiões do Brasil. Piracicaba: Escola Superior de Agricultura "Luiz de Queiroz", 2002. 85p. Dissertação (Mestrado em Irrigação e Drenagem) - Escola Superior de Agricultura "Luiz de Queiroz", 2002.

SANTOS, M.V.F.; DUBEUX Jr., J.C.B.; SILVA, M.C. Produtividade e composição química de gramíneas tropicais da Zona da Mata de Pernambuco. Revista Brasileira de Zootecnia, v.32, n.4, p.821-827, 2003.

SILVA, D.J. Análise de alimentos (métodos químicos e biológicos). 2.ed. Viçosa, MG: Universidade Federal de Viçosa, 1990. 165p. 